\title{
Erratum to: Hardy-Littlewood-Polya's Inequality and a New Concept of Weak Majorization
}

Ionel Rovenţa

Erratum to: Mediterr. J. Math. 13(2016), 573-583 DOI 10.1007/s00009-015-0524-4

In the original article the funding acknowledgements was missed.

\author{
Acknowledgements \\ Ionel Rovenţa \\ Department of Mathematics \\ University of Craiova \\ 200585 Craiova, Romania \\ e-mail: ionelroventa@yahoo.com
}

The author is supported by Romanian National Authority for Scientific Research CNCS-UEFISCDI research project PN-II-RU-TE-2014-4-1109.

The online version of the original article can be found under doi:10.1007/s00009-0150524-4. 